JJTM, Vol. 7 No.3 Tahun:2019

\title{
ANALISA PENGARUH LAJU ALIRAN FLUIDA AIR PADA SALURAN PIPA AHU (AIR HANDLING UNIT) TERHADAP CAPAIAN SUHU OPTIMUM MESIN PENDINGIN MINI WATER CHILER
}

\author{
Made Dwi Kayana 1, I Nyoman Pasek Nugraha 2, Kadek Rihendra Dantes 3. \\ Jurusan Pendidikan Teknik Mesin, Fakultas Teknik dan Kejuruan \\ Universitas Pendidikan Ganesha \\ Singaraja, Indonesia \\ e-mail :dwikayana11@gmail.com, pasek nugraha@undiksha.ac.id, \\ Rihendra dantes@undiksha.ac.id
}

\begin{abstract}
Abstrak
Penelitian ini Penelitian ini bertujuan untuk mengetahui variasi laju aliran fluida air terhadap capaian suhu optimal mesin pendingin Mini Water Chiler yang di hasilkan pada siklus sekunder. Adapun variasi laju aliran fluida air yang digunakan yaitu variasi laju aliran air 0,27 liter/detik, 0,55 liter/detik, dan 0,83 liter/detik..pengumpulan data pada penelitian ini dilakukan setiap 20 menit sebanyak 20 kali. Dari hasil penelitian didapatkan penggunakan variasi laju aliran fluida air 0,27 liter/detik,0,55 liter/detik, dan 0,83 liter/detik pada AHU 1 adalah $26,43^{\circ} \mathrm{C}$ $: 19,33^{\circ} \mathrm{C}: 13,43^{\circ} \mathrm{C}$. Pada AHU 2 adalah $26,33^{\circ} \mathrm{C}: 19,22{ }^{\circ} \mathrm{C}: 13,33^{\circ} \mathrm{C}$. Pada AHU 3 adalah $26,23^{\circ} \mathrm{C}: 19,12^{\circ} \mathrm{C}: 13,23^{\circ} \mathrm{C}$. Dari pengujian di atas didapatkan penggunaan laju aliran fluida air 0,83 liter/detik menghasilkan suhu paling optimal dibandingkan dengan laju aliran fluida air 0,27 liter/detik dan 0,55 liter/detik, hal ini disebabkan semakin cepat laju aliran fluida air maka semakin optimal suhu yang di capai Mini Water Chiller dan penyerapan panas pada setiap ruangan akan menjadi maksimal.
\end{abstract}

Kata Kunci : Mini Water Chiler, Laju Aliran Fluida, Capaian Suhu Optimal

\begin{abstract}
This study tries to study the variation of air fluid flow to the optimal temperature of Mini Water Chiler cooling machines produced in the secondary cycle. The variations in the air flow rate of the air used are variations in air flow rates of 0.27 liters / second, 0.55 liters / second, and 0.83 liters / second. The data analysis technique in this study uses one-way variation analysis. Data collection in this study was carried out every 20 minutes 20 times. From the results of the study obtained using variations in air fluid flow rate 0.27 liters / second, 0.55 liters / second, and 0.83 liters / second in AHU 1 is 26.430C: 19.330C: 13.430C. In AHU 2 is 26.330C: 19.22 OC: 13.330C. In AHU 3 is 26.230C: 19.120C: $13.230 \mathrm{C}$. The water flow of 0.83 liters / second produces an optimal flow of water fluid 0.27 liters / second and 0.55 liters / second, this results in increased fluid flow velocity then the optimal temperature achieved by the Mini Water Chiller and heat at each the room will be maximal.
\end{abstract}

Keywords: Mini Water Chiler, Fluid Flow Rate, Optimal Temperatur Achievement 


\section{Pendahuluan}

Mini Water Chiler adalah mesin pendingin rancangan mahasiswa prodi pendingin jurusan Pendidikan Teknik Mesin undiksha, yang memiliki fungsi hampir sama dengan mesin water chiler pada umumnya namun pada rancangan ini mesin water chiler dibuat secara mini atau prototype, mesin ini mempunyai ukuran rangka dengan panjang $100 \mathrm{~cm}$, lebar $50 \mathrm{~cm}$, dan tinggi 130 $\mathrm{cm}$. Mini Water Chiler dirancang dengan memodifikasi AC Split, kapasitas kompresor yang digunakan adalah 1PK. Pada Chiled water tank supply menggunakan kaca yang dilapasi steroform, tujuannya memakai kaca sebagai Chiled water tank supply adalah untuk memudahi kepada pengamat untuk mengamati cara kerja evaporator yang direndam didalam Chiled water tank supply, ukuran Chiled water tank supply yaitu dengan panjang $84 \mathrm{~cm}$, tinggi $30 \mathrm{~cm}$, dan lebar $30 \mathrm{~cm}$. Untuk ruangan yang didinginkan menggunakan 3 ruangan mini yang dibuat menggunakan steroform, panjang ruangan yaitu $30 \mathrm{~cm}$, lebar $33 \mathrm{~cm}$, dan tinggi $50 \mathrm{~cm}$.

\section{Kompresor}

Kompresor pada mesin chiller adalah jantung dari system refrigrasi yang berfungsi untuk mengsirkulasikan refrigerant dalam system chiller. Kompresor juga berfungsi untuk menghisap uap refrigerant yang keluar dari evaporator dan menaikan tekanan uap refrigerant yang keluar dari evavorator dan menaikan tekanan uap refrigerant agar titik embunnya naik diatas temperature medium pendingin.

\section{Kondensor}

Kondensor pada chiller berfungsi untuk memindahkan panas dari system refrigrasi ke media pendingin yang digunakan. Pada kondensor ini gas atau uap refrigerant yang memiliki tekanan dan temperature yang tinggi.

\section{Katup Expansi}

Katup expansi pada chiller berfungsi untuk menurunkan tekanan dari refrigerant melalui katup expansi ini terjadinya perubahan tekanan tinggi ke tekanan rendah. Selain itu katup expansi juga berfungsi untuk mengontrol refrigerant yang masuk ke dalam evaporator.

\section{Evaporator}

Evaporator adalah komponen yang merupakan tempat untuk refrigerant menguap untuk menyerap panas dari udara, air ataupun bahan lainnya.

\section{Pompa Sirkulasi}

Pompa sirkulasi pada chiller berfungsi untuk mensirkulasikan air dingin dari chiller menuju pada koil pendingin Air Handling Unit $(\mathrm{AHU})$.

\section{Cooling Tower}

Cooling tower adalah komponen pada system chiller yang berfungsi untuk mendinginkan air panas yang sebelumnya melewati AHU.

\section{Air Handling Unit (AHU)}

Fungsi AHU adalah mesin penukar kalor antara air dingin dengan udara. Pada proses ini, udara panas dari dalam ruangan dihembuskan oleh browel untuk melewati coil pendingin pada AHU. Sehingga membuat udara yang dihasilkan menjadi udara dingin.

\section{Pipa}

Pipa yang digunakan pada Mini Water Chiler adalah pipa tembaga, pipa memiliki fungsi sebagai sistem instalasi untuk tempat mengalirnya media - media pada Mini Water Chiler.

\section{Solenoid Valve}

Solenoid pada Mini Water Chiler sebagai katup otomatis yang berfungsi untuk mengaliri atau menghentikan laju aliran air yang di pompa menuju $A H U$.

\section{Metode Penelitian}

Metode yang akan digunakan dalam penelitian ini adalah metode eksperimen. Metode eksperimen merupakan bagian dari metode kuantitatif, dan memiliki ciri khas 
JJTM, Vol. 7 No.3 Tahun:2019

tersendiri terutama dengan adanya kelompok kontrol. Dalam bidang sains, penelitian-penelitian dapat menggunakan desain eksperimen karena variabel-variabel dapat dipilih dan variabel-variabel lain yang dapat mempengaruhi proses eksperimen itu dapat dikontrol secara ketat. Sehingga dalam metode ini, peneliti memanipulasi paling sedikit satu variabel, mengontrol variabel lain yang relevan, dan mengobservasi pengaruhnya terhadap variabel terikat.

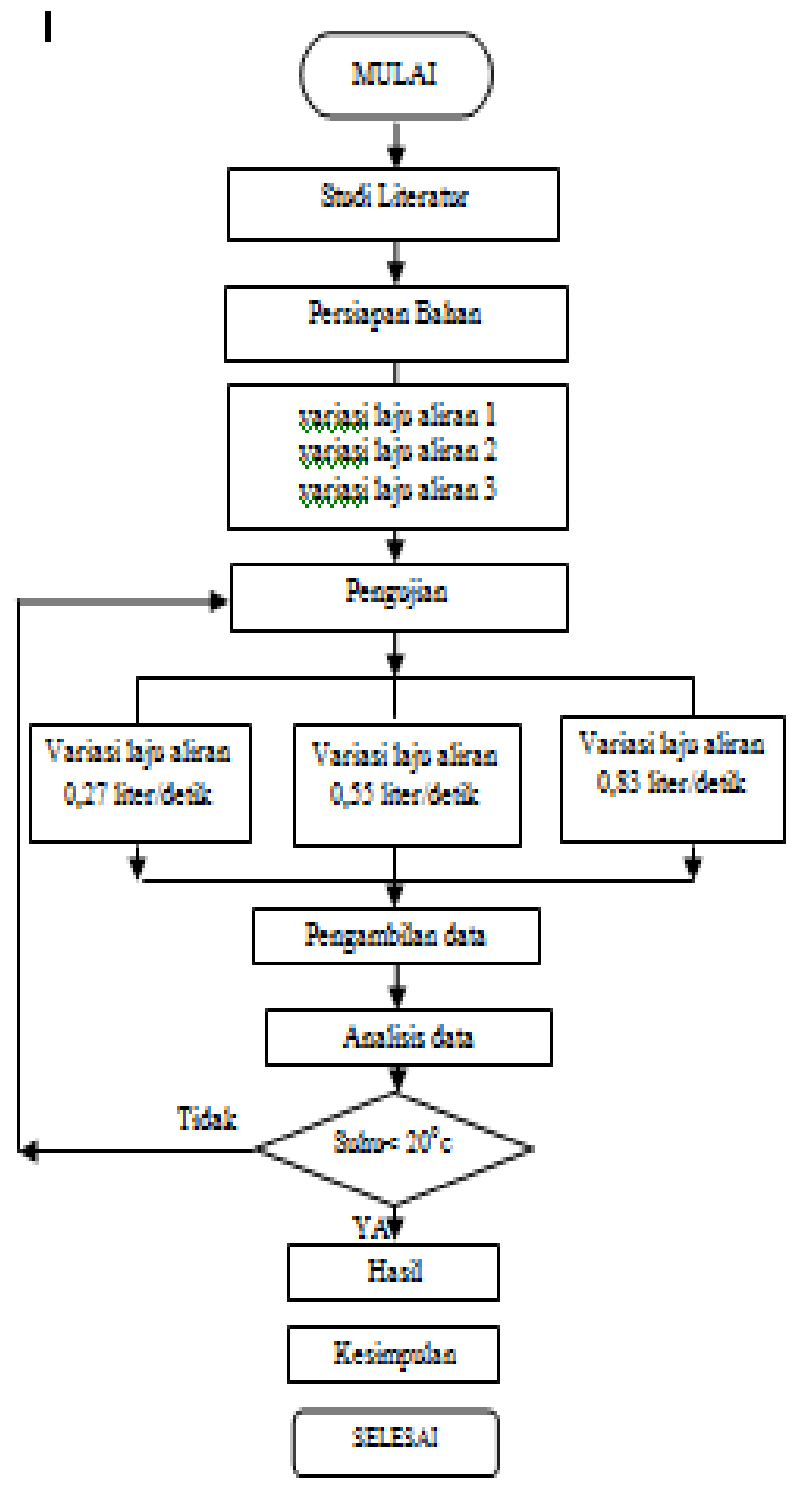

Alat dan Bahan
a. Mini Water chiller
b. Pompa Sirkulasi
c. Thermometer Digital
d. Stopwatch

\section{Hasil dan Pembahasan}

1) Data Hasil Pengujian di $A H U 1$

\begin{tabular}{|c|c|c|c|}
\hline \multirow{2}{*}{$\begin{array}{c}\text { Pengujia } \\
\text { n Setiap } \\
\text { 20 Menit }\end{array}$} & \multicolumn{3}{|c|}{ Suhu yang dicapai $\left({ }^{0} \mathrm{C}\right)$} \\
\cline { 2 - 4 } & $\begin{array}{c}\text { Laju } \\
\text { aliran } \\
0,27 \\
\text { liter/deti } \\
\text { k }\end{array}$ & $\begin{array}{c}\text { Laju } \\
\text { aliran } \\
0,55 \\
\text { liter/deti } \\
\text { k }\end{array}$ & $\begin{array}{c}\text { Laju } \\
\text { aliran } \\
0,83 \\
\text { liter/deti } \\
\text { k }\end{array}$ \\
\hline 1 & 26,4 & 19,3 & 13,4 \\
\hline 2 & 26,4 & 19,3 & 13,4 \\
\hline 3 & 26,4 & 19,3 & 13,4 \\
\hline 4 & 26,4 & 19,3 & 13,4 \\
\hline 5 & 26,6 & 19,3 & 13,4 \\
\hline 6 & 26,4 & 19,5 & 13,4 \\
\hline 7 & 26,4 & 19,3 & 13,6 \\
\hline 8 & 26,4 & 19,3 & 13,4 \\
\hline 9 & 26,4 & 19,3 & 13,4 \\
\hline 10 & 26,6 & 19,4 & 13,4 \\
\hline 11 & 26,4 & 19,3 & 13,4 \\
\hline 12 & 26,4 & 19,3 & 13,4 \\
\hline 13 & 26,4 & 19,3 & 13,4 \\
\hline 14 & 26,4 & 19,3 & 13,5 \\
\hline 15 & 26,4 & 19,5 & 13,4 \\
\hline 16 & 26,4 & 19,3 & 13,4 \\
\hline 17 & 26,5 & 19,3 & 13,6 \\
\hline 18 & 26,4 & 19,3 & 13,4 \\
\hline 19 & 26,4 & 19,3 & 13,4 \\
\hline 20 & 26,4 & 19,3 & 13,4 \\
\hline TOTAL & 528,5 & 386,5 & 268,5 \\
\hline Rata- & & & \\
\hline Rata & 26,43 & 19,33 & 13,43 \\
\hline & & & \\
\hline
\end{tabular}


2) Data Hasil Pengujian di $A H U 2$

\begin{tabular}{|c|c|c|c|}
\hline \multirow{2}{*}{$\begin{array}{c}\text { Pengujia } \\
\text { n Setiap } \\
\text { 20 Menit }\end{array}$} & \multicolumn{3}{|c|}{ Suhu yang dicapai $\left({ }^{0} \mathrm{C}\right)$} \\
\cline { 2 - 4 } & $\begin{array}{c}\text { Laju } \\
\text { aliran } \\
0,27 \\
\text { liter/deti } \\
\text { k }\end{array}$ & $\begin{array}{c}\text { Laju } \\
\text { aliran } \\
0,55 \\
\text { liter/deti } \\
\mathrm{k}\end{array}$ & $\begin{array}{c}\text { Laju } \\
\text { aliran } \\
0,83 \\
\text { liter/deti } \\
\mathrm{k}\end{array}$ \\
\hline 1 & 26,3 & 19,2 & 13,3 \\
\hline 2 & 26,3 & 19,2 & 13,3 \\
\hline 3 & 26,3 & 19,2 & 13,3 \\
\hline 4 & 26,3 & 19,2 & 13,3 \\
\hline 5 & 26,5 & 19,2 & 13,3 \\
\hline 6 & 26,3 & 19,3 & 13,3 \\
\hline 7 & 26,3 & 19,2 & 13,5 \\
\hline 8 & 26,3 & 19,2 & 13,3 \\
\hline 9 & 26,3 & 19,2 & 13,3 \\
\hline 10 & 26,5 & 19,3 & 13,3 \\
\hline 11 & 26,3 & 19,2 & 13,3 \\
\hline 12 & 26,3 & 19,2 & 13,3 \\
\hline 13 & 26,3 & 19,2 & 13,3 \\
\hline 14 & 26,3 & 19,2 & 13,4 \\
\hline 15 & 26,3 & 19,3 & 13,3 \\
\hline 16 & 26,3 & 19,2 & 13,3 \\
\hline 17 & 26,4 & 19,2 & 13,5 \\
\hline 18 & 26,3 & 19,2 & 13,3 \\
\hline 19 & 26,3 & 19,2 & 13,3 \\
\hline 20 & 26,3 & 19,2 & 13,3 \\
\hline TOTAL & 526,5 & 384,3 & 266,5 \\
\hline Rata- & & & \\
\hline Rata & 26,33 & 19,22 & 13,33 \\
\hline & & & \\
\hline
\end{tabular}

3) Data Hasil Pengujian di $A H U 3$

\begin{tabular}{|c|c|c|c|}
\hline \multirow{4}{*}{ Pengujia } & \multicolumn{3}{|c|}{ Suhu yang dicapai $\left({ }^{\circ} \mathrm{C}\right)$} \\
\cline { 2 - 4 } n Setiap & Laju & Laju 3 & Laju \\
20 Menit & aliran & aliran & aliran \\
& 0,27 & 0,55 & 0,83 \\
& liter/deti & liter/deti & liter/deti \\
& $\mathrm{k}$ & $\mathrm{k}$ & $\mathrm{k}$ \\
\hline 1 & 26,2 & 19,1 & 13,2 \\
\hline 2 & 26,2 & 19,1 & 13,2 \\
\hline
\end{tabular}

\begin{tabular}{|c|c|c|c|}
\hline 3 & 26,2 & 19,1 & 13,2 \\
\hline 4 & 26,2 & 19,1 & 13,2 \\
\hline 5 & 26,4 & 19,1 & 13,2 \\
\hline 6 & 26,2 & 19,2 & 13,2 \\
\hline 7 & 26,2 & 19,1 & 13,4 \\
\hline 8 & 26,2 & 19,1 & 13,2 \\
\hline 9 & 26,2 & 19,1 & 13,2 \\
\hline 10 & 26,4 & 19,2 & 13,2 \\
\hline 11 & 26,2 & 19,1 & 13,2 \\
\hline 12 & 26,2 & 19,1 & 13,2 \\
\hline 13 & 26,2 & 19,1 & 13,2 \\
\hline 14 & 26,2 & 19,1 & 13,3 \\
\hline 15 & 26,2 & 19,2 & 13,2 \\
\hline 16 & 26,2 & 19,1 & 13,2 \\
\hline 17 & 26,3 & 19,1 & 13,4 \\
\hline 18 & 26,2 & 19,1 & 13,2 \\
\hline 19 & 26,2 & 19,1 & 13,2 \\
\hline 20 & 26,2 & 19,1 & 13,2 \\
\hline TOTAL & 524,5 & 382,3 & 264,5 \\
\hline Rata- & \multicolumn{2}{|c|}{} & \\
Rata & 26,23 & 19,12 & 13,23 \\
\hline
\end{tabular}

4) Hasil Capaian Suhu Mini Water Chiler di AHU 1 menggunakan variasi laju aliran fluida air 0,27 liter/detik, 0,55 liter/detik, dan 0,83 liter/detik.

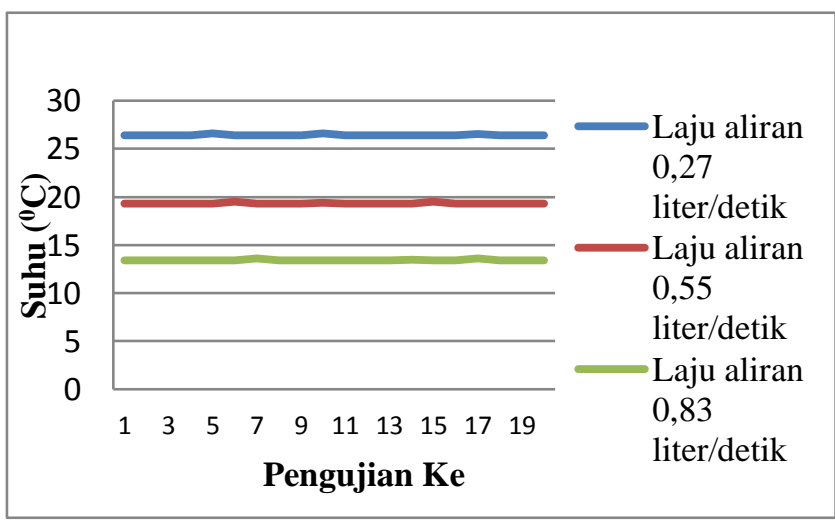

Dari gambar grafik hasil pengujian di atas suhu yang dicapai Mini Water Chiler menggunakan variasi lajua liran fluida air 0,27 liter/detik. 0,55 liter/detik, dan 0,83 liter/detik Rata-rata suhu yang dicapai pada AHU 1 :

a. 0,27 liter/detik $=26,43^{\circ} \mathrm{C}$

b. 0,55 liter/detik $=19,33^{\circ} \mathrm{C}$

c. 0,83 liter/detik $=13,43^{\circ} \mathrm{C}$ 
JJTM, Vol. 7 No.3 Tahun:2019

5) Hasil Capaian Suhu Mini Water Chiler di AHU 2 menggunakan variasi laju aliran fluida air 0,27 liter/detik, 0,55 liter/detik, dan 0,83 liter/detik

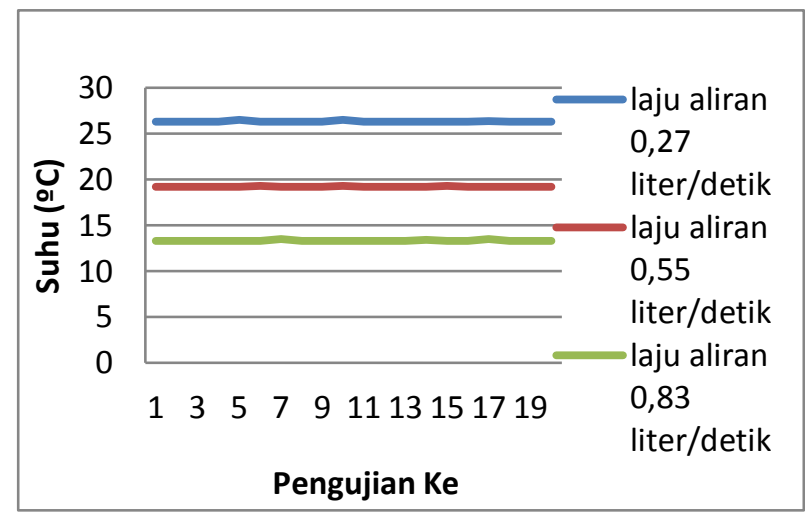

Dari gambar grafik hasil pengujian di atas suhu yang dicapai Mini Water Chiler menggunakan variasi lajua liran fluida air 0,27 liter/detik. 0,55 liter/detik, dan 0,83 liter/detik Rata-rata suhu yang dicapai pada AHU 2 :

a. 0,27 liter $/$ detik $=26,33^{\circ} \mathrm{C}$

b. 0,55 liter/detik $=19,22^{\circ} \mathrm{C}$

c. 0,83 liter/detik $=13,43^{\circ} \mathrm{C}$

6) Hasil Capaian Suhu Mini Water Chiler di AHU 3 menggunakan variasi laju aliran fluida air 0,27 liter/detik, 0,55 liter/detik, dan 0,83 liter/detik.

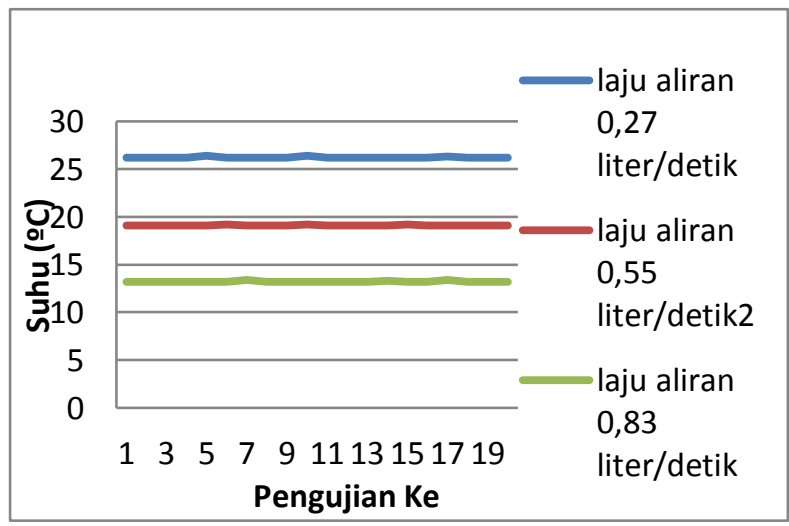

Dari gambar grafik hasil pengujian di atas suhu yang dicapai Mini Water Chiler menggunakan variasi lajua liran fluida air 0,27 liter/detik. 0,55 liter/detik, dan 0,83 liter/detik Rata-rata suhu yang dicapai pada AHU 3 :

a. 0,27 liter/detik $=26,23^{\circ} \mathrm{C}$

b. 0,55 liter/detik $=19,12^{\circ} \mathrm{C}$

c. 0,83 liter/detik $=13,23^{\circ} \mathrm{C}$

\section{Pembahasan}

Setelah melakukan analisa berdasarkan data dan grafik mengenai suhu ditemukan bahwa kecepatan aliran mempunyai pengaruh yang signifikan terhadap capaian suhu optimal dari Mini Water Ciler . Ini dikarenakan semakin cepat aliran fluida air maka semakin cepat juga pendinginan yang terjadi di $A H U$ sehingga suhu yang dihasilkan optimal.. Hal ini juga dibuktikan dengan analisa berdasarkan table uji Tukey didapatkan bahwa pada penggunaan laju aliran fluida air 0,83 liter/detik lebih berpengaruh terhadap suhu optimal dibandingkan dengan menggunakan kecepatan aliran 0,55 liter/detik dan 0,27 liter/detik. Suhu teredah didapatkan menggunakan laju aliran fluida air 0,83 liter/detik adalah $13,2^{\circ} \mathrm{C}$

\section{Kesimpulan}

Berdasarkan hasil penelitian dan pembahasan diatas, dapat disimpulkan.

1. Dari pengujian diatas didapatkan penggunaan laju aliran fluida air 0,83 liter/detik menghasilkan suhu paling optimal dibandingkan dengan laju aliran fluida air 0,27 liter/detik dan 0,55 liter/detik, hal ini disebabkan semakin cepat laju aliran fluida air maka semakin optimal suhu yang di capai Mini Water Chiller dan penyerapan panas pada setiap ruangan akan menjadi maksimal.

2. Terdapat pengaruh penggunaan variasi laju aliran fluida air 0,27 liter/detik terhadap capaian suhu optimal mesin pendingin mini water chiler dibuktikan dengan nilai $Q$ hitung $=1.001,40$ lebih besar dari $Q$ tabel $=3,40$ ( $Q$ hitung $>Q$ tabel).

3. Terdapat pengaruh penggunaan variasi laju aliran fluida air 0,55 liter/detik terhadap capaian suhu optimal mesin pendingin mini water chiler dibuktikan dengan nilai $Q$ hitung $=1.830,98$ lebih besar dari $Q$ tabel $=3,40(Q$ hitung $>Q$ tabel).

4. Terdapat pengaruh penggunaan variasi laju aliran fluida air 0,83 liter/detik terhadap capaian suhu optimal mesin pendingin mini water chiler dibuktikan dengan nilai $Q$ hitung $=829,57$ lebih 
besar dari $Q$ tabel $=3,40(Q$ hitung $>Q$ tabel)

\section{Saran}

Untuk mendapatkan suhu yang lebih rendah, sebaiknya menggunakan pompa yang sesuai dengan kinerja mesin

\section{Daftar Rujukan}

Arikunto. 2006. Prosedur Penelitian Suatu Pendekatan Praktek. Jakarta : Pt. Rineka Cipta.

Ali Nugroho.Judul : "Analisa Kinerja Refrigerasi Water Chiler Pada Pt Gmf Aeroasia" :2015

Azridjal Aziz .Judul: "Studi Eksperimental Mesin Refrigrasi Siklus Kompresi Uap Menggunakan Refrigerant Hidrokarbon Substitusi R22 Pada Kondisi Transient" : 2009

Basri, Hasan. 2009. Efek Perubahan Laju Aliran Masa Air Pendingin Pada Kondensor Terhadap Kinerjamesin Refrigerasi Focus 808. Bandung: Pustaka Setia

Dantes, Nyoman. 2014. Analisis Dan Desain Eksperimen (Disertai Contoh Penerapan Analisis Data). Singaraja Program Pasca sarjana Undiksha.

Koyan, I Wayan. 2012. Statistika Pendidikan (Teknik Analisis Data Kuantitatif). Singaraja : Universitas Pendidikan Ganesha.

Rasta I Made. 2011. Pengaruh Laju Aliran Volume Chilled Water Terhadap Ntu Pada Fcu Sistem Ac Jenis Water Chiller Di Politeknik Negeri Bali.
Yuli Setyo Indartono, "Perkembangan Terkini Teknologi Refrigerasi Pengkondisian Udara (Ac)", 2006, Www.Beritaiptek.Com. 